\title{
Empowerment and Rights-Based Social Work Interventions for Widows in Zimbabwe: A Literature Review
}

\author{
Misheck Dube ${ }^{1}$ \\ ${ }^{1}$ Department of Social Work, Lifestyle Diseases Entity, Faculty of Health Sciences, North-West University \\ (Mafikeng Campus), Republic of South Africa
}

Correspondence: Misheck Dube, North-West University (Mafikeng Campus), P. Bag X2046, 2735, South Africa. Tel: 27-183-892-983. E-mail: Misheckdube@gmail.com; Misheck.Dube@nwu.ac.za

$\begin{array}{lc}\text { Received: February 7, } 2019 & \text { Accepted: April 8, } 2019 \quad \text { Online Published: May 6, } 2019 \\ \text { doi:10.5539/gjhs.v11n6p94 } & \text { URL: https://doi.org/10.5539/gjhs.v11n6p94 }\end{array}$

\begin{abstract}
Due to the patriarchal and oppressive nature of the communities, Zimbabwean widows need interventions through empowerment and rights-based approaches. This article argues that those in rural area such as Binga District are more prone to oppression and widowhood has a greater impact on them as they lack the necessary resources coupled with lack of prioritisation in professional interventions. With the aim of refocusing social work interventions on empowerment and rights of widows, the article reviews literature from various sources to discuss how social work may intervene. Literature is reviewed thematically to give structure and to ensure focus on relevant discussion points. This revealed the current perspectives on widowhood elucidating on the loopholes existing within these perspectives suggesting that a more comprehensive and context specific understanding of widowhood is needed especially taking into account the young generation of widows in Zimbabwe that needs empowerment and rights-based intervention approaches. This paper has shown that such social work interventions are possible as it is a professional and ethical requisite to intervene where people are marginalised and oppressed in an endeavor to restore their worth and dignity.
\end{abstract}

Keywords: widows, oppression, empowerment, rights-based approaches, interventions

\section{Introduction}

The phenomenon of widowhood is not new both locally in Binga District in Zimbabwe and globally. The attempted understanding of widowhood and discourses of literature and peace meal interventions have sadly been used as source of funding by humanitarian agencies for peace meal interventions. Whilst social work as a discipline has deficient literature on widowhood and interventions needed, disciplines such as psychology, sociology and the nursing profession, and humanitarian organisations like the United Nations (UN) have attempted to pay some attention to the phenomenon of widowhood but in less practical terms for meaningful interventions. Similarly, governments of many African nations including the Zimbabwean government, have ratified international conventions, such as the Convention on the Elimination of All forms of Discrimination Against Women of 1979 and the Beijing Platform of Action of 1995 and the Maputo Protocol and have also put legal frameworks, usually fragmented and less enforced, in place to protect the rights of women in general yet little has been achieved protecting the rights of widows. This denotes the extent to which the phenomenon deserves attention as a problem.

Widowhood has been described as one of the world's "epidemics," (Widows for Widows, 2011) as it cuts across continents, regions, countries, provinces, districts and municipalities in the geographic sense. Demographically, widowhood is a phenomenon experienced by every race, age cohort, and ethnic group, tribal and religious group. According to Widows for Widows (2011), there are approximately " 245 million widows in the world with 115 million living in extreme poverty." Due to the hardships experienced by widows, the UN, on $23^{\text {rd }}$ of June 2011 , officially declared $23^{\text {rd }}$ June an International Widows' Day (p.5).

\section{Problem Statement}

Empowerment and rights of oppressed individuals are a buzz word in social work. Whilst there is a general acknowledgement of oppressed and marginalised, (DuBois \& Miley, 2014), people receiving various interventions through social work services, the empowerment of widows has not been synonymous with social work 
interventions in Binga District in Zimbabwe. The district is remote and under resourced with non-governmental organisations (NGOs), devoid of social work professionals, dominating humanitarian assistance to the needy. This means social work interventions are needed as widows in the district are mostly young, discriminated and isolated because the local communities associate them with the spirit of the dead (Dube, 2011). They are oppressed to an extent that they cannot inherit the property left behind by their deceased husbands leaving them economically destitute and unable to meet their everyday life needs and the needs of their children. Sadly, the rights of the widows are often not recognised often stripping away their human dignity and worth, thereby militating against the values of social work. This gives space for an investigation to unearth the injustices faced by widows, discuss and propose possible empowerment based approaches social workers can use to intervene for the plight of the widows.

\section{Aim of the Study}

This paper aims at generating debates on the lack of empowerment and rights-based social work interventions of the oppressed widows in Binga District in Zimbabwe. The hope is that this paper will stimulate empowerment and rights based approaches that social workers can use in intervening in the mayhem.

\section{Methodology}

This paper reviewed an arsenal of literature from many fields and disciplines. Journal articles and published social work books, humanitarian agency reports, and websites exposing the plight of widows. Useful literature on empowerment and rights-based social work interventions were also reviewed. The literature were purposefully selected around the essential thematic areas of discussion to allow focus and depth. The reviewed literature were not more than ten years old. Literature older than ten years from the date of publication could not be used as they were regarded as outdated.

\section{Discussions}

Central to the discussions in this paper are the two common perspectives to widowhood in social work literature which become a point of departure to the questions raised and arguments levied on widowhood. Further expositions of injustices the widows experience contributing to their psychosocial ill-health are done to create space for the need for social work interventions with special emphasis on empowerment and rights-based social work interventions.

\section{Perspectives on Widowhood}

As a point of departure, it can be a gross conceptual mistake to ignore a critical comprehension of widowhood from different perspectives. The prominent perspectives to widowhood are twofold in social work literature. The first one adopts the developmental perspective whilst the second one embraces the social justice perspective.

\subsection{The Human Developmental Perspective}

Currently, social work literature on widowhood has aligned itself with the human development perspective. This perspective has tended to discuss widowhood in the context of old age (Keister \& Destro, 2008 (cited in Dube, 2016), Martin-Matthews, 2011; Zastrow \& Kirst-Ashman, 2013). The discourses of widowhood from the human developmental perspective have viewed widowhood as a normal human development curve where at some point in a woman's old age, a partner eventually dies leaving her widowed as part of the human development course.

The developmental perspective contends that widows exist because men tend to die earlier than women as they are likely to marry younger women and in terms of general life expectancy, women tend to live longer than men. To enable adjustment to older widowhood, Zastrow and Kirst-Ashman (2013, p.636) have noted that "keeping busy, doing volunteer work, taking new paying positions and taking part in community programmes" are better options for older widows. For socialization and interactional purposes, support groups for the aged are encouraged to facilitate adjustment and healing in the widows' problems.

While the human developmental perspective to the problems of widowhood provides essential lens for intervention on older widows, an evaluation of the human developmental perspective to current trends in widowhood in an African context especially in Zimbabwe, lacks an additional and equally important focus on the young widows. The focus on the older widows may not be sufficient for social work practice in Sub-Saharan contexts as the trends in widowhood have changed. There is a growing number of young widows, especially in Zimbabwe where girls and young women are now widows. It is argued in this paper that the young widows require the essential empowering programmes and services of social workers as their life demands differ from an old generation of widows. From that line of thought, it is important to note that this paper endorses the importance of viewing widowhood from young age right through to the old age so that the phenomenon is understood comprehensively and relevant social work interventions are put in place. 


\subsection{The Social Justice Perspective}

Social justice is described as the value of social work upon which the foundation of the profession is built (DuBois \& Miley, 2014). Values in social work guide what social workers do. In this regard, social justice is regarded as of primary importance and beholden to the profession of social and embraced by practitioners to guide their professional conduct. This is significant in social work interventions in widows' challenges as justice is less experienced in their psychosocial predicaments. To indicate the importance of social justice to the profession of social work, the National Association of Social Workers (NASW) and the International Federation of Social Workers (IFSW) place social justice as a practice imperative (DuBois \& Miley, 2014). The social workers' ethical code also mandates social workers to promote and commit themselves to social justice. This undoubtedly can accord widows of their human rights which are literally extinct in Binga District in Zimbabwe.

Whilst there is no agreement among authors on the definition of social justice, a common feature is that social justice centres on the fairness doctrine and principle. Some useful and relevant definitions of social justice are provided by Robinson and the National Pro Bono Resource Centre. Robinson $(2015, \mathrm{p} .1)$ sees social justice as:

...promoting a just society by challenging injustice and valuing diversity. It exists where all people share a common humanity and therefore a right to equitable treatment, support their human rights, and a fair allocation of community resources.

The National Pro Bono Resource Centre (2011, p.2) sensitises that social justice should be understood to be "fairness beyond individual justice." The primacy of these definitions is their emphasis on the concept of "fairness" which is a critical concept in relation to treatment of widows in the African context and in Zimbabwe where widows receive differential treatment because of the stigma associated with widowhood.

National Pro Bono Resource Centre (2011, p.6) provides a critical analysis of what structural definitions of social justice should entail with specific mechanisms for governments in dealing with social justice by suggesting:

1) Fair redistribution of resources,

2) Equal access to opportunities,

3) Fair system of law and due process,

4) Protection of vulnerable and disadvantaged people.

This analysis of social justice provides a critical approach to addressing the plight of widows from a systematic structural institutional level which is one of the ineffective mechanisms in Zimbabwe. The responses to the plight of widows has not met optimal level to address their needs.

Whilst the structural level is important to understanding the concept of social justice, it is important also to understand the concept at individual level. The understanding of social justice at individual level provides a better understanding of the concept of social justice as justice or injustice is normally felt at individual level by the widows.

The National Pro Bono Resource Centre (2011) underscores the fact that individuals need to get what they deserve if social justice has to be achieved. This is in respect of the resources that are commensurate with people's social status and position. Further a consideration of those who are poor and excluded from resource allocation is important. The organisation also mentions the need for recognition of contributions made by the individual as important in determining their rightful share of resources. This is generally lacking in Zimbabwe where property inheritance is precarious for the widow and needs to be resolved no matter what contribution the widow has made in the acquisition of property in the marriage. Equally important is the determination of the individual capacity and personal characteristics in utilising available opportunities and resources. This could assist intervention efforts by social workers to mirror the capacities of the individual widows in attaining social justice.

\subsection{Preventing Social injustices to Promote Social Justice}

It is the social work mandate to prevent human suffering by preventing social injustices. The experience of widows in their everyday lives is what the profession of social work fights against. Social work exercises its professional mandate so that victims can live fulfilling lives. The injustices society exerts on people are known as "ISMS" normally defined as the "prejudicial attitudes directed against groups that society identifies as less capable, less productive and less normal" (DuBois \& Miley, 2014, p.137). Some of the social injustices faced by certain groups of people in society are racism, elitism, heterosexism, ageism, handicapism and sexism. Whilst all social injustices should be prevented by social workers, this paper focuses on "sexism" which in the researcher's view has significant contribution to the psychosocial health of the widows. 


\subsubsection{Prevention of Sexism to Promote Social Justice for the Widows}

The subornation of the female sex has an untraceable history. It has existed throughout human existence and continues to exist even today with an ever enduring presence. This societal state of affairs has been condemned by professional advocates of equality between sexes, such as social work professionals, and it is currently discussed as sexism. By means of definition, sexism is seen by DuBois and Miley (2014, p.139) as:

...the belief that one sex is superior to the other. Sexism most frequently manifests as prejudicial attitudes toward and discriminatory actions against the females, giving gender privilege to men.

Sexism is blamed upon the process of socialization of children where boys are socialised differently from girls. DuBois and Miley (2014 p.139) perceive gender socialisation as a process that "confers power on men and relegates women to a second-class status". The operationalisation of sexism transcends human knowledge to cite biblical scriptures in order for men to secure maximum subservience from women by using the sacredness and power of religion.

Whilst it is not directly referred to in social work literature, sexism is directly linked to the suffering of widows and inferences can be made that the psychosocial plight of widows stems from sexism which is very prevalent in many African societies, including Zimbabwe.

\subsubsection{Widowism as a Social Injustice}

Literature reviewed has indicated that the existence of widows is a global phenomenon and an epidemic of its own. Further, there is widespread abuse and oppression of widows compared to widowers. Also, a widower finds it easy to re-marry than a widow (Johnson \& Shyamala, 2012; Martin-Matthews, 2011) due to stigma attached to the female whose spouse has died.

Sexism can be viewed as a determinant in analysing and drawing conclusions about the abuse of widows in Zimbabwe due to the widespread existence of sexism as a social injustice. Following that line of thought, this paper posits that a new social injustice, "widowism," can be coined and rightfully viewed as a direct offshoot from sexism. "Widowism" as a social injustice can then be explained as a practice which dehumanises, devalues, discriminates and views widows with suspicion resulting in exclusion in socio-economically beneficial activities and exposing them to socially harmful practices. The oppressive and dehumanising experience of widows in the developing nations such as horrible widow cleansing, property grabbing, isolation, burning, witchcraft accusations and land evacuations, (Idialu, 2012; Mgbako \& Glenn, 2011; Peterman, 2012), cannot be ignored and as such intervention by social workers is crucial for their psychosocial wellbeing.

\subsection{The Effects of Social Injustices on Widows}

An analysis of the effects of social injustices provides a crucial point of departure for social work empowerment and rights-based approaches to intervene and ameliorate the effects of social injustices on the widows. To this effect, an analysis of the effects of social injustices on the victims provided by DuBois and Miley (2014) is very helpful in providing a clear and significant understanding of widows' experiences of social injustices. This paper argues that social injustices on widows result in discrimination, oppression and victimization.

\subsubsection{Oppression of Widows Through Discrimination}

Immediately a woman becomes a widow, unbalanced power between other community members and the widow exists. The widow experiences discrimination, subjugation and oppression (DuBois \& Miley, 2014) through cultural practices from psychologically powerful and advantaged members of the community resulting in social and psychological domination. The widow then becomes so oppressed that she cannot stand up for her human rights, including the rights to economic resources. It is important to note the existence of differential power between the widows and the oppressor where the widow is always at the powerless end of the continuum of oppression.

\subsubsection{Interpersonal Dehumanisation}

A closer examination of the experiences of widows in Zimbabwe and other developing states brings to the argument that their ordeals equal interpersonal dehumanisation. People dehumanise others "by regarding others with cold detachment and showing indifference to human misery and dehumanisation obscures the inherent worth and dignity of personhood" (DuBois \& Miley, 2014, p.150). At a more extreme level, dehumanisation projects other people as non-living objects.

From this point on dehumanisation, widows of Binga District in Zimbabwe are reduced to objects as they cannot voice their concerns. The cultural dictates in the district are so intense and powerful such that they obscure the 
legal protection of the widows from humiliating and dehumanising treatment (Johnson \& Shyamala, 2012). The story of the Regional Integration Minister Priscilla Misihairambwi-Mushonga in Zimbabwe is one classical example where she was a victim of property grabbing after the death of her husband Doctor Christopher Mushonga (Rusere, 2010). The Minister admitted that she could not pursue the case of inheriting her husband's property due to culture. This indicates the dominance of culture over law in Zimbabwe for women in Zimbabwe despite their social status. From this case, a projection can be made of the intensity of oppression of less educated widows in rural communities of Binga District where oppressive culture is normalised.

With reference to the Shona culture in Zimbabwe, Kambarami (2006) as cited by Dube (2016) identifies the dehumanising treatment of widows when they are forced into levirate marriage upon the death of their husbands. Again in this context, their consent to marry the brother of the deceased husband is a normative cultural expectation that cannot be contested or they risk being sent back to the natal family after being shamed. The dehumanising effects of widowhood create conditions in which widows find themselves less accepted as human beings deserving better treatment in the communities and even their own natal families.

\subsubsection{Personal Victimisation}

The process of personal victimisation is painful to the widows. Widows succumb to the negative labels and connotations (DuBois \& Miley, 2014) that society ascribe to widowhood. This makes the widows to live up to the labels given to them. One such label is that once the spouse dies, the woman is said to be dirty and needs to be cleansed through traditional rituals. The widow herself succumbs to the fact that she is dirty by virtue of being a widow and such personal blame results in intense feelings of inferiority, dependency and rejection by the community (DuBois \& Miley, 2014).

Psychologically, stigmatisation destroys a widow's self-esteem and engenders a sense of powerlessness. It can be argued that the widows at this point identify themselves with oppression and internalise it as acceptable, thereby reinscribing powerlessness in themselves. Due to this personal victimisation, widows then find themselves alienated and isolated from social circles. This is often the case in Binga District in Zimbabwe where women's social networks and friends dwindle as soon as the status of widowhood sets in their lives. In this respect, the natural mechanisms and social circles for coping with widowhood is drastically reduced.

\subsection{Coping With the Psychological Effects of Social Injustice}

A critical dimension to the analysis of the effects of social injustice is the understanding of the psychological effect that it has for the widows. A professional social worker is expected to understand these effects so that proper empowerment, rights-based interventions can be put in place. An analysis of coping with the lasting psychological effects of social injustices is documented by Cohen (2014) who provides important dimensions that can be helpful in dealing with the effect of social injustices on the widows. The approach provides a critical and necessary point of departure in understanding the deep rooted effects of social injustices.

The approach provides psychological effects of social injustices and then basic coping mechanisms adopted by the widows as victims not necessarily an antidote that immediately cures the psychological effects of such social injustices. The bottom line is that social workers need to facilitate coping with social injustices in their empowerment rights-based approaches and that they need to understand these psychological effects. The discussion in the succeeding paragraphs highlights some helpful insights about the psychological effects of social injustices widows are exposed to.

\subsubsection{Pain}

According to Cohen (2014), oppression and subordination produce pain resulting from the trauma associated with it. Pain in this regard is experienced physically and emotionally. Similarly widows experience torture that brings both emotional and physical pain. This pain experienced by the widows trains them to remain subordinate in the social system in order to avoid further pain associated with widowhood. The pain is experienced at individual psychic level and undermines the widow's personhood and transforms her into what Cohen (2014) terms a "pain-avoiding mechanism" (p.269).

It is also important to note that the pain produced by social subordination of the widows can be dealt with in a similar way as with general trauma, but an important aspect is that it has effects of disempowerment and alienation upon the widows. Also most importantly is the fact that subornation of widows is socially legitimized and this further legitimizes pain and injuries inflicted onto the widows as a socially acceptable culture. Cohen (2014p.269) suggests that dealing with such pain of the social injustices levied against the victims begins with "delegitimising" such acts and "voicing" it. On the part of the widow as a victim, the starting point of the coping process is to understand and recognise that her experience is not what she deserves. 
Principal to coping with pain brought about by the social injustices is the flexibility capacity of the social worker to facilitate "within-community support and solidarity" and meaningful relationships. The researcher calls the social workers intervention expertise "flexibility capacity" because the skills to be employed should be versatile and adaptive to different circumstances characterising different communities. The social worker needs also to enable the widows to voice the "unvoiceable" in order to facilitate community respect for the widows (Cohen, 2014, p.269).

\subsubsection{Fear}

Fear, as a psychological output of social injustices, plays a significant role in maintaining subservience and subjugation of the widows. Fear in the widows to seek recourse and demand their rights maintains the social structures of oppression. This goes with rewards to the oppressor as there are minimal possibilities to overturn the status quo. In expressing how widows are gripped by fear to challenge their oppression, Cohen (2014 p.270) puts it well by describing fear as a "deterrence-based approach to maintaining social order." This fear to challenge oppression by widows is not superficial and not to be taken lightly and blamed on them. It should be understood within the context of the socialisation process of the girl child in Zimbabwe and other many oppressive societies where she is culturally expected to be obedient and unquestioning to authority. This internalized socialisation transcends beyond the girl at home, to a wife and then to a widow.

In addressing this psychological fear, the social worker needs to possess special skills to provide the widows with a sense of comfort and security both physical and emotional (Cohen, 2014). There is also a need for social workers to activate some aspects of courage to face and accept the reality of widowhood. The widows have to be compelled to ignite and resuscitate innate abilities to cope with their challenges and reduce this manifestation of psychological fear.

\subsubsection{Shame}

Shame is one lasting effect of social injustices experienced by widows. It is a direct result of social constructions of the widowhood status in that it is culturally understood to be the worst status a woman can find herself in. Noticeably in many studies, widows are described as unclean, sometimes blamed for killing their husbands, accused of witchcraft, forced to sleep with the deceased body and are isolated from social circles (Brewer, 2011; Lomba, 2014; Nwabueze, 2010). The powerlessness that the widows experience is unquestionably a profound source of shame as they lack the power to take control of their lives.

Social work interventions in cases of shame must centre on reducing shaming the widows, creating conditions of community acceptance and acknowledging the widowhood status by the people that are influential in their lives. Empowerment of widows can also be a crucial component of social work intervention.

\subsubsection{Anger}

Cohen (2014 p.273) maintains that anger is a "natural by-product of social subordination, a natural result of emotions such as pain, fear, and shame." In other words, widows experience anger automatically for the pain inflicted upon them. They fear to challenge their oppression and the dehumanising embarrassment they experience after the death of their husbands. Much of the anger is felt and noticeable when widows ask themselves rhetorical questions such as why they are being treated in that way and whether they are not as human as other people. Such rhetorical questions exacerbate the psychological pain and are derivatives of the injustices experienced by the widows.

Anger derived directly from the abuse and injustices inflicted on the widows is what Cohen (2014, p.273) termed "primary" anger. More than that primary form is another anger which results from lack of recourse to justice systems. This is profoundly common in African countries and other developing states. Oppressors inflict pain on the widows and no proper remedies are in place. Lack of recourse to justice makes the widows hopeless and produces "secondary" anger. This secondary anger becomes a source of danger to the lives of the widows and is a high predictor of self-injury commonly experienced as suicide.

Coping with such an injustice is not easy for widows. Widows have been seen to supplicate their plight to the spiritual realm, hoping that God righteously punishes the oppressor (Cohen, 2014). Social workers could help widows also to vent out anger in a helpful manner which may be a source of empowerment and promote taking relevant action.

\subsubsection{Despair}

Arguably, despair is one of the most difficult states of the psychic turmoil of widows usually synonymous with hopelessness and anguish. At conventional level, despair is thought to be tied to sadness but Cohen (2014, p.274) 
argues that it is "deeper and more lasting than sadness." Usually it is as a result of the understanding that this injustice is not going to end with the widow but further affects the widow's children where recourse is nigh improbable.

Coping with despair is understood to be a realisation of the widows about what they can and are able to do with their social circumstances and widowhood. Because widowhood has already set in, Cohen (2014) warns that it is not helpful for them to struggle to change the situation, but rather to understand what they can do about their situation. Social work intervention therefore should centre on empowerment processes so that the widows understand their strengths and alternative ways of coping with their situation rather than succumb to despair.

\section{Approaches Guiding Interventions in the Psychosocial Plight of the Widows}

Social work intervention for the psychosocial plight of the widows is essential. The profession of social work holds and is guided by specific approaches for guiding intervention. The rights and the empowerment approaches are useful in guiding social work interventions in the psychosocial challenges faced by the widows.

\subsection{The Rights Approach to Social Work Intervention}

The question of Human Rights in the African context is very critical. The dominance of harmful culture in the region and rejection of Western philosophies to handling of African issues has always been of political interest in African states. Despite the importance of Human Rights for the welfare of the people in Africa, the fact that they originate in the West, normally viewed as colonisers in Africa, lends them to scrutiny with suspicion in various countries. The results are that each country has its own achievements and loopholes in terms of observing Human Rights as required by the United Nations. In an attempt to observe Human Rights, different treaties and conventions have been ratified by the various states and differently incorporated into their laws and policies which results in variations in Human Rights questions and issues in respective countries. That being the case, Zimbabwe has not accorded widows their inherent Human Rights to be enjoyed.

Scholars have not agreed on what is meant by the term "right" and such definitional imprecision has influenced the rights approaches and understanding of Human Rights (Mbondenyi, 2011). Words such as "important, moral and universal" have been used to define right which lends itself to controversy because what is right in one community may necessarily not be right in another (Mbondenyi, 2011, p.14). Right can be defined in abstract or concrete senses. Mbondenyi (2011, p.17) shares that:

...in abstract sense, right refers to justice, ethical, correctness, or consonance with the rule of law or principles of morals. In concrete sense it means power, privilege, faculty or demand inherent in one person and incidental upon another.

It is therefore based upon the discussed definitions of what right means which lends to the conclusion that rights are either morally or legally grounded. On that note, Mbondenyi (2011, p.17) concedes to the definition that human rights are:

...the demands or claims individuals or groups make that are essential for individual wellbeing, dignity, and fulfillment the deprivation of which may lead to a great affront to justice.

No matter which definition of Human Rights any scholar may subscribe to, the conclusion is that Human Rights are "inherent, indivisible, interrelated, universal, and belong to every society regardless of geographical, historical, cultural, ideological, political and economic orientation" (Mbondenyi, 2011, p.18). This conclusion from the author dispels the justification of oppressing the widows by any society defending itself on the basis on any factor. This is why it is important that Human Rights be observed by any society or community for the wellbeing of its people particularly vulnerable people like the widows in Zimbabwe.

This paper acknowledges the existence of many theories attempting to make accounts of what rights are and their origin. However, this paper takes the Liberty and Equality: Choice theory approach to explain the Social Work approach in dealing with the psychosocial problems experienced by the widows in Zimbabwe.

Central to Choice theory is the concept of liberty and equality of human beings. This is fundamental, especially to the oppressed widows in Zimbabwe. In-as-much as equality and liberty are related terms, their components differ. Equality is dominantly understood to mean "non-discrimination" in such a way that people have equal "moral and legal standing" in the communities (Fagan, 2009, p.15). From this perspective, people's equality is not earned but they possess it inalienably and it is not determined by factors such as "race, gender, ethnicity, physical capabilities, religious or ideological commitments" (Fagan, 2009, p.15).

Another aspect of the Choice theory is the concept of liberty which leans much on negative liberty and positive liberty. Negative liberty demands "non-interference in an individual's private sphere" (Fagan, 2009, p.15). This 
means that people's freedom needs to be extended to be free in their minds and thoughts from coercion and even from any external influence such as political influence. Positive liberty on the other hand centres on actualisation of this situation where an individual can set goals and pursue them without influence of the external forces (Fagan, 2009).

Since liberty is central to Human Rights, both negative and positive liberty have a very significant role on the rights of people. These two concepts reinforce and enforce the notion that if rights of people have to be fully accorded to them, then there is need to avoid interference in their lives and that people should be given the opportunity to actively formulate their own life goals and pursue them. Taping from that perspective, widows in Zimbabwe need to be liberated from abuse and oppression and they need to be allowed to make choices in their lives without interference and be able to purse personally structured goals for them to be able to live a fulfilling life.

The Choice theory also asserts that human rights are of highest significance and chief to all other moral contemplations because they entail the rights of every human being. From the Choice theory's assertion, the qualification for having human rights is simple in that the theory holds that "being human entails the possession of human rights" (Fagan, 2009, p.16). This interpreted differently means that when human beings are deprived of their human rights, their humanness is jeopardised. All human beings are expected to hold and accept that all other human beings, such as the widows, have human rights simply because of their human nature. This is simply because human rights are inherent in human beings and as such, depriving them of human rights means reducing them to objects and "a failure of rationality" in the suppressor of human rights (Fagan, 2009, p.17).

\subsection{Empowerment Approach}

The empowerment approach, sometimes called the strength-based perspective, to the psychosocial problems of the widows is very critical in intervening in their problems. This approach is central to social work practice and has been widely utilised in the profession and considers clients' innate inner strengths rather than the deficit approach to their problems (Saleeby, 2009). To engage the strengths perspective in social work intervention with the widows, it is important to grasp the meaning of the word strength. Kondrat (2010, p.39) cites Greene and Lee (2002, p.182) who define strength as:

...the capacity to cope with difficulties, to maintain functioning in the face of stress, to bounce back in the face of significant trauma, to use external challenges as a stimulus for growth, and to use social supports as a source of resilience.

\subsection{Understanding the Language of Strengths}

Saleeby (2009) makes it clear that social workers need to understand the vocabulary and language of strengths for them to be in a better position and be competent in assisting their clients such as the widows. The writer notes plasticity, empowerment, membership, resilience, healing and wholeness, dialogue and collaboration and suspension of disbelief as important vocabulary to understand. A salient concept in strengths of people is the concept of empowerment. This is the basis for the interventions for the psycho-social problems of the widows. According to Saleeby $(2009$, p.11), empowerment refers to "the intent to, the processes of, assisting individuals, groups, families, and communities to discover and expend the resources and tools within and around them". Stated differently empowerment requires that the environment be responsive enough to provide opportunities to the clients to choose and that the person needs to be aware of such options. Therefore social workers need to understand that for the widows to be empowered there is need to provide them with necessary resources and options to deal with their challenges. These resources need to be explored within their environment and widows should be assisted to understand the possibility and availability of these resources and options.

At another level, the empowerment of the widows requires that the social workers deal with the endemic, deep seated strains and struggles in the communities that subdue and limit the widows to live a fulfilling life. This means that the community which normally is a source of stress and abuse to the widows needs to be targeted for interventions as discussed earlier in the macro level interventions.

The concept of membership is another central term to be comprehended. Membership gives people that social workers help a sense of belonging. Clients feel valued and a sense of belonging into the community. It is always the case that widows feel isolated in the communities because of loss of their husbands and people do not want to associate with them as they are regarded as dirty and unclean. This inculcates in them a sense of alienation. For empowering the widows, the understanding of membership should motivate the social work practitioner to have inclination towards enforcing the "rights, responsibilities, assurances and securities" of the widows (Saleeby, 2009, p.11). The social worker needs to organise groups to which these widows can belong and be members, such as the 
support groups, in an attempt to foster the sense of belonging.

People exposed to abuse normally soldier on with life through resilience. Saleeby $(2009, \mathrm{p} .12)$ asserts that for human beings, resilience is "not an exception" but it is how human beings recover from trouble. In demanding situations such as the psychosocial problems experienced by the widows, it means that there is need for acknowledging their situations and traumatic life experiences and continue to bear with the ordeals they are facing. Social workers should assist the widows to continue to grow and taping on their capacities to grow out of adversity and fostering ability to meet the demands and challenges of their life experiences.

Saleeby (2009) alerts professionals of healing and wholeness that happens to the body and mind when faced with difficulties. The writer asserts that healing and wholeness is the body's inherent capability when faced with adversity. Social workers have to understand that even though widows face abuse and trauma in their lives, their bodies have the natural tendency to heal. The social workers' task is to facilitate the healing process through professional support.

Another important conceptual aspect of the strengths in people is dialogue and collaboration. In dialogue and collaboration, emphasis is on the fact that people grow and develop through their meaningful relationships with other people. The relationship with other people enables comparison and testing of one's ability to that of other people (Saleeby, 2009). Dialogue would require that the community recognises widows as people with dignity and as such gives them equal respect with other people of the community which is a fertile ground for healing and empowerment. Collaborations requires that social workers work with the widows in tackling their challenges. Social workers become "agents and consultants" in the pursuit for healing by the widows in their challenging situations (Saleeby, 2009, p.14).

There also a need to suspend disbelief of the stories of the widows. The social worker has work with the mindset that what the widows say a true reflection of their challenges. Disbelieving what the widows say about their experiences jeopardises the helping process and defeats the purpose of the engagement with them as clients in the helping process. "Suspension of disbelief", (Saleeby, 2009, p.14), helps the social worker to have an objective approach to the helping process and fosters starting where the clients is.

\subsection{The Principles and Assumptions of the Strengths Perspective}

This paper endorses that when assisting clients, social workers are guided by professional principles which give the practitioner and operational philosophy. The strengths perspective has also operational principles which guide the practitioners' actions in assisting their clients. Kondrat (2010, p.40) provides a summary of the guiding principles of the strengths perspective which are:

- Every individual, group, family and community has strengths.

- Trauma, abuse, illness and struggle may be injurious, but they may also be sources of challenge and opportunity.

- Assume that you do not know the upper limits of the capacity to grow and change and take individual, group, and community aspirations seriously.

- We best serve our clients by collaborating with them.

- Every environment is full of resources.

- Caring, caretaking, and context-care is essential to human well-being.

The most significant helping philosophy in social work practice using the strengths perspective is that social workers need to work collaboratively with their clients (Kondrat, 2010). This means that social workers helping the widows to deal with the psychosocial challenges experienced in their communities need to have a collaborative working relationship with them for the helping process and social work intervention to be effective.

Kondrat (2010) takes the operational guiding principles provided by Kisthardt (2009) as essential operational guidelines in social work interventions using the strengths perspective. The principles the author provides are discussed below.

1. The initial focus of the helping process is on the strengths, interests, abilities, knowledge and capabilities of each person not their diagnosis, deficits, symptoms and weaknesses as defined by another (Kondrat, 2010, p.41). Using this principle in assisting the widows means that while it is important for the social worker to understand empathetically the widows' challenges, the social worker needs to focus more on what the widows are capable of doing rather than devoting much attention on the abuses they are experiencing from the community. Devoting much effort and attention to what widows are able to do empowers them and increase hope in them and makes 
them see themselves as capable human beings in solving their problems. Kondrat (2010, p.41) suggests that social workers need to start this process by "showing respect, and admiration for clients and taking an interest in clients' hope, dreams and aspirations".

2. The helping relationship becomes one of collaboration, mutuality and partnership. Power with another, not power over another (Kondrat, 2010). The primary point of departure in helping the widows using the strengths perspective is that social workers should not assume a position of power over the widows. They need to embrace the fact that widows know better about their suffering and as such they are experts in their challenges. Social workers need to work collaboratively with the widows to foster a sense of hope in them and cultivate energy to see themselves as capable to overcome life ordeals.

3. Each person is responsible for his or her own recovery. The participant is the director of the helping efforts. We save as caring community living consultants. The healing process takes place on many levels (Kondrat, 2010). This principle gives power to the client to lead the helping process because they know better what needs to change in their lives. Clients also understand their aspirations and needs. Following this principle means that social workers need to give the widows leeway to lead the helping process because they know their problems better. Allowing the widows to take a lead in the interventions in their plight makes them more engaged, they feel important and they feel listened to which is important for empowering them and hence the chances of succeeding with interventions are very high.

4. All human beings have the inherent capacity to learn, grow, and change (Kondrat, 2010). Oppressive societies always give people labels which makes them feel as if they are not capable individuals among them. These labels makes social work clients feel unimportant and incapable individuals amongst other people in the community (Kondrat, 2010). Likewise, widows are labeled as unclean and need to be cleaned and generally isolated from other members of the families and community on the basis that they are widows and have bad spells of the dead. Such labels undermine their selfhood and lower their self-esteem and subject them to abuse. Social workers need to help widows to understand that they have the capacity to change their situations and beliefs of the community about widowhood which cannot disable them from personal growth and living a fulfilling life.

5. Helping activities in naturally occurring settings in the community are encouraged (Kondrat, 2010, p.42). The major emphasis in this principle is that social workers need to help their clients within their communities. Resources and networks for sustaining the interventions are inherent in the communities in which the clients reside. From that perspective, social workers dealing with the psycho-social problems of the widows should also master the use of the community to de-stigmatise widowhood, gain community acceptance and respect for the widows, foster and sustain healthy relationships between the widows and the communities. This is critically important for sustainability of interventions and future prevention of possible abuse of the widows.

6. The entire community is viewed as an oasis of potential resources to enlist on behalf of service participants. Naturally occurring resources are considered as a possibility first, before segregated or formally constituted 'mental health' or 'social services' (Kondrat, 2010, p.42). This principle emphasises the belief that all environments, including the one which is a source of troubles for the clients, have necessary resources to assist the clients. Kondrat (2010, p.42) argues that in the environments where clients' problems emanate:

...there are individuals, associations, groups and institutions who have something to give, something that others need: knowledge, succour, an actual resource or talent, or simply time and place.

In view of the psychosocial challenges of the widows, this principle endorses the fact that there is need for the social worker to maintain a positive view of the communities that abuse widows. There is need to scan for helpful systems and resources available within the communities and use the same facilities to help the widows. The very abusive community can be a succulent source of nurturing environment to the widows. The main task of the social worker is to help the widows tap those resources for personal adjustment, growth and further development.

\section{Conclusion}

This paper concludes that conceptualisation of widowhood has been marred by feminisation of the phenomenon in Binga District of Zimbabwe. A fundamental conclusion is reached that social work intervention in the psychosocial problems of the widows is very critical for their psychosocial wellbeing. Other disciplines have attempted to assist the widows to deal with their problems, however, the psychosocial component of the problems of the widows needs an empowerment rights-based social work intervention. The normalisation of widowhood and confining it to the developmental perspective has little significance in Sub-Saharan Africa such as the situation in Zimbabwe due to a rapid increase in the number of young widows. This paper has provided an alternative conceptualisation of the phenomenon which is potentially helpful for helping professionals. 
An extensive description and analysis of how social work interventions can be used to deal with the challenges faced by the widows in Zimbabwe has been done. Most importantly the paper also highlighted and evaluated the critical psychosocial struggles of the widows whilst providing essential Social Work approaches to ameliorate the widows' plights.

\section{Acknowledgements}

My sincere gratitude goes to the late Professor Nomonde-Phetlho-Thekisho for mentoring me in achieving this research project and making this study a success. May her soul rest in eternal peace!

The National Research Foundation (NRF) stretched its resources and made sure that the finding of the study are shared with the international audience in Istanbul in Turkey in Dubai 2017. This sharped my ideas and views on the study. My gratitude goes to NRF without which the findings of the study would not have gained international recognition.

\section{Competing Interests Statement}

The authors declare that there are no competing or potential conflicts of interest.

\section{References}

Brewer, K. (2011). The Challenges faced by widows. United Kingdom: Widows Rights International. Retrieved from https://www.widowsrights.org/researchdocumentkbrewerr0911.pdf

Cohen, J. (2014). Coping with lasting social injustice. Washington and Lee Journal of Civil Rights and Social $\begin{array}{lllll}\text { Justice, } & \text { 13(2) 260-283. } & \text { (Revised). } & \text { Retrieved }\end{array}$ https://papers.ssrn.com/sol3/papers.cfm?abstract_id=1332128.

Dube, M. (2011). Widowhood and Property Inheritance in Zimbabwe: A study of Sikalenge Ward, Binga District. Dudweiler Landstr: LAMBERT Academic Publishing.

Dube, M. (2016). The psycho-social plight of widows in Binga District in Zimbabwe: the efficacy of social work intervention (Thesis-PhD). Mafikeng: North West University. http://hdl.handle.net/10394/24924.

DuBois, B., \& Miley, K. K. (2014). Social Work: An empowering profession (8th ed). Boston: Pearson.

Fagan, A. (2009). Human rights: Confronting myths and misunderstandings. Cheltenham: Edward Elgar. https://doi.org/10.4337/9781849802000

Idialu, E. E. (2012).The inhuman treatment of widows in African communities. Current Research Journal of Social Sciences, 4(1), 6-11. Retrieved from http://maxwellsci.com/print/crjss/v4-6-11.pdf

Johnson, E. J., \& Shyamala, J. N. W. (2012). Widow remarriage: A New dimension of social change in India. International Journal of Humanities and Social Sciences, 2(3), 195-205. Retrieved from https://www.researchgate.net/publication/233389356

Kondrat, D. C. (2010). The strengths perspective. In B. Teater (Ed.), An introduction to applying Social Work theories and methods (pp. 38-53). England: McGraw Hill.

Lomba, P. (2014). Widow cleansing in Malawi. American International Journal of Contemporary Research, 4(1), 34-40. Retrieved from http://www.aijcrnet.com/journals/Vol_4_No_1_January_2014/6.pdf

Martin-Matthews, A. (2011). Revisiting widowhood in later life: Changes in patterns and profiles, advances in research and understanding. Canadian Journal on Aging/La Revue canadienne du vieillissement, 30(03), 339- 354. https://doi.org/10.1017/S0714980811000201

Mbondenyi, M. K. (2011). International human rights and their enforcement in Africa. Nairobi: Law Africa.

Mgbako, C. A., \& Glenn, K. (2011). Witchcraft accusations and human rights: Case studies from Malawi. The Geo. Wash. Int'l L. Rev, 43, 389-417. Retrieved from https://ir.lawnet.fordham.edu/faculty_scholarship/399.

National Pro Bono Resource Centre. (2011). What is social justice? Occasional paper \#1. Retrieved from http://www.bing.com/search?q=whatissocialjusticepdfdownload\&PC=RIMBINGD\&A=results.

Nwabueze, R. N. (2010). Securing widows' Sepulchral rights through the Nigerian constitution. Harvard Human Rights Journal, 23, 141-155. Retrieved from http://harvardhrj.com/wp-content/uploads/2010/10/141-156.pdf.

Peterman, A. (2012). Widowhood and asset inheritance in Sub-Saharan Africa: Empirical evidence from 15 Countries. Development Policy Review, 30(5), 543-571. https://doi.org/10.1111/j.1467-7679.2012.00588.x 
Robinson, M. (2015). What is social justice? Retrieved from http:/gjs.appstate.edu/social-justice-and-human-rights/what-social-justice.

Rusere, P. (2010). Despite legislation, Zimbabwean widows often unable to assert property rights. Retrieved from http://www.voazimbabwe.com/content/zimbabwean-inheritance-fail-to-protect-women--94509559/1456490 .html

Saleeby, D. (2009). Power in the people. In Saleeby, D. (ed.), The strengths perspective in Social Work practice (5th ed., pp. 1-23). Boston: Pearson.

Saleeby, D. (2009). The strengths perspective in Social Work Practice (5th ed.). Boston: Pearson Education.

Widows for Widows. (2011). International Widows Day at the UN. Retrieved from http://www.unwomen.org/en/news/stories/2011/6/international-widows-day-23- june-2011

Zastrow, C. H., \& Kirst-Ashman, K. K. (2013). Understanding human behaviour and the social environment (9th ed.). Australia: Brooks/Cole.

\section{Copyrights}

Copyright for this article is retained by the author(s), with first publication rights granted to the journal.

This is an open-access article distributed under the terms and conditions of the Creative Commons Attribution license (http://creativecommons.org/licenses/by/4.0/). 